\title{
CURRÍCULO: ENTRE TEORIAS E MÉTODOS
}

\author{
JOSÉ AUGUSTO PACHECO
}

Professor do Instituto de Educação da Universidade do Minho - Braga, Portugal

jpacheco@iep.uminho.pt

\begin{abstract}
RESUMO
Em um momento de intensa globalização, em que se impõem novos padrões e novos conceitos, o currículo ganha uma outra centralidade educacional, sobretudo se for considerado da perspectiva da noção de conhecimento. Procura-se, neste artigo, debater questões ligadas à teorização e ao método do currículo, destacando-se quer as teorias críticas e de instrução, sempre cruzadas com a racionalidade tyleriana e o relativismo, quer o currere como espaço de discussão. CURRÍCULO - TEORIA - MÉTODO - GLOBALIZAÇÃO
\end{abstract}

\begin{abstract}
SCHOOL CURRICULUM: BETWEEN THEORIES AND METHODS. At a time of intense globalization, when new patterns and new concepts are being proposed, the school curriculum has gained a new educational centrality particularly when one considers it from the perspective of notion of knowledge. This article aims at discussing issues related to curriculum theorizing and method, emphasizing either the critical and teaching theories, always interconnected with the Tylerian rationale and the relativism, or currere, as a space for discussion.

CURRICULUM - THEORY - METHOD - GLOBALIZATION
\end{abstract}

Este artigo foi redigido a partir da conferência apresentada no $4^{\circ}$ Colóquio Luso-Brasileiro sobre Questões Curriculares, Universidade Federal de Santa Catarina, 2 a 4 de setembro de 2008. 
A Fundação Calouste Gulbenkian promoveu um ciclo de conferências em torno do Estado do Mundo, orientadas por olhares disciplinares muito diversos, e publicadas no livro A urgência da teoria, com o propósito de fazer a "apropriação do espaço público como espaço privilegiado para a apresentação e discussão das teses ou aporias que questionem as múltiplas dimensões das sociedades contemporâneas, dos seus atores, das suas práticas [e] dos seus desejos" (Bhabha et al., 2007, p.II).

Nenhuma das lições eruditas e não opinativas, como se assinala no prefácio, diz respeito à Educação, apesar da importância que lhe é atribuída, pelo menos no nível da retórica política, pelos governos nacionais e pelos organismos transnacionais e supranacionais. A ausência da Educação, ou das Ciências da Educação, para referir-me à nomenclatura mais utilizada atualmente em Portugal, dos debates científicos sobre o Estado do Mundo não significará a sua fragilidade conceitual, quando comparada com outras áreas do conhecimento, mas, ao contrário, o difícil caminho da sua cientificidade, como, aliás, tem enfatizado Albano Estrela (1992, 1999).

Este texto, pensado a partir de algumas contribuições do ciclo de conferências, porque a Educação também tem uma palavra a dizer na análise das problemáticas contemporâneas, está organizado em três pontos fundamentais: o recuo e urgência da teoria no campo educacional em contextos de globalização; a pluralidade teórica no campo curricular, com destaque para as teorias críticas; a discussão do método como forma de construção do currículo. Os dois últimos pontos são explorados a partir da contribuição de William Pinar, uma das vozes mais influentes na discussão dos Estudos Curriculares.

\section{RECUO E URGÊNCIA DA TEORIA}

Em seus últimos escritos acadêmicos, Maria Célia Moraes abordou, de forma consistente e apaixonada', o recuo da teoria, tendo como prioridade denunciar que o conhecimento e a ciência estão sob ameaça, em particular as ciências humanas e sociais, com base nesta crítica:

I. "Pois bem, os temas que me perseguem há anos, muito próximos entre si, são o da ciência e o da produção do conhecimento. A eles venho dedicando toda minha atividade acadêmica, minhas pesquisas e publicações, aulas, orientações de teses e dissertações - tanto assim que após todos esses anos gosto de pensar que meu tema já persegue também outros pesquisadores que ajudei a formar" (Moraes, 2008, p. I). Ver também Moraes, 200 I. 
Contexto de ceticismo epistemológico e de relativismo ontológico que hoje nos cerca compromete acentuadamente a capacidade de as ciências superarem suas próprias antinomias tanto no plano explanatório como no do enfrentamento prático de seus problemas. Este fato, de meu ponto de vista, leva a um empobrecimento da atividade cognitiva, como veremos a seguir e, mais ainda, à constatação, de que o sucesso da direita no terreno da filosofia da ciência e da sociedade não se deve apenas a seu êxito em alcançar o domínio político; sob a aparência de um novo realismo, ela apropriou para si até mesmo o conceito de realidade e de realismo. (2008, p. I)

No entanto, e sem entrar por ora na questão do relativismo, frequentemente relacionado com as teorias pós-modernas ${ }^{2}$, como mostra Maria Célia Moraes, o recuo da teoria está relacionado igualmente à globalização, sobretudo quando entendida como um processo de transformação, segundo Giddens (2007), de natureza econômica, política e cultural, de acordo com Ritzer (2007), e como "um estado de transição que rompe com as nossas formas de conhecer o mundo em que vivemos" (Bhabha, 2007).

É possível dizer que o estado do mundo é globalizado, apoiando-se seja na crença de que o conhecimento é um valor econômico adicionado, na medida em que o ponto fulcral da competitividade residiria na economia do conhecimento, seja na "fé praticamente cega no poder da inovação tecnológica e da comunicação global" (Bhabha, 2007, p.3l).

Tenta-se impor a ideia de que a terra é plana e de que o mundo, em face do poder suave dos mercados globais, é uma imensa planície sem obstáculos para que a mão invisível de Adam Smith possa regular a oferta e a procura.

É nesse sentido que se falará de um mercado global, de uma cultura mundial, de um conhecimento funcional e, ainda, de uma Grande Teoria. Uma Teoria vinculada à homogeneização da realidade social, não tanto herdeira do racionalismo kantiano, quando se aceita a existência de categorias universais que definem o modo de entender o mundo, mas prisioneira da "otimização

2. Para Boudon (2009, p.7-8), "o relativismo é considerado uma doutrina adequada num mundo pós-colonial, em vias de globalização, que afirma que todas as culturas se equivalem e onde o individualismo tende a impor a ideia de que tudo é opinião e de que toda a opinião merece respeito. Não haveria verdades incontestáveis senão no mundo da técnica". 
das performances", isto é, da busca da "melhor relação entre input/output" no contexto da abertura de um "vasto mercado de competências operacionais", nas palavras de Jean-François Lyotard ( 2006, p.8I e p.93) em seu livro fundador das teorias pós-modernas, lançado em 1979.

É neste ponto que Maria Célia Moraes analisa o recuo da teoria, assinalando que o mundo neoliberal aborda a educação em uma perspectiva instrucional e funcional:

Não basta apenas educar, é preciso assegurar o desenvolvimento de "competências" (transferable skills), valor agregado a um processo que, todavia, não é o mesmo para todos. Para alguns, exige níveis sempre mais altos de aprendizagem, posto que certas "competências" repousam no domínio teórico-metodológico que a experiência empírica, por si só, é incapaz de garantir. Para a maioria, porém, bastam as "competências", no sentido genérico que o termo adquiriu hoje em dia, o de saber tácito, que permitem a sobrevivência nas franjas do núcleo duro de um mercado de trabalho fragmentado, com exigências cada vez mais sofisticadas e formidáveis níveis de exclusão. (2008, p.3)

Trata-se, de fato, de um movimento centrado no realismo empírico e, por conseguinte, na gestão científica, com base nos pressupostos teóricos de Frederick Taylor (191 I), e na mercantilização do conhecimento. Assim, a escola passa a funcionar segundo princípios e práticas da lógica de mercado ${ }^{3}$.

Analisando-se os efeitos da globalização na educação, observa-se que a escola, sutil e progressivamente, age segundo certas regras de mercado e impulsiona a ideia de que somente a competitividade dos resultados, balizados por um núcleo central de saberes pragmáticos, pode solucionar os problemas da economia. É neste sentido que o instrumentalismo técnico é uma ideologia que a globalização partilha e impõe às instituições educacionais, "um estilo de regulação gerencial" associado a um aparato mais amplo de indicadores de performance, de formulação de metas e de estabelecimento de tabelas comparativas" (Moore, Young, 200I, p.20l).

3. Desenvolve-se esta lógica, no quadro de outras lógicas e modelos de racionalidade, em Pacheco, 2003. 
Outra razão para o recuo da teoria, e ainda segundo Maria Célia Moraes, deve-se à adoção de teorias pós-modernas, cujos limites de compreensão da realidade são definidos

...pela empiria das tarefas cotidianas, pela formatação da capacidade adaptativa dos indivíduos, pela narrativa descritiva da experiência imediata e busca da eficácia na manipulação do tópico [...] Nessa perspectiva cética e relativista, o mundo social é esvaziado de qualquer dimensão estrutural duradoura que apenas o esforço teórico pode alcançar. Por conseguinte, a teoria que se constrói, nivelada em seu conjunto por indiferenciado relativismo, restringe-se a descrever e, quando muito, a nomear as formas fenomênicas do cotidiano. (2008, p.3)

A defesa do particularismo relaciona-se comumente ao entendimento de que a experiência é a base do conhecimento e de que a subjetividade é o único caminho de que o sujeito dispõe para a análise e compreensão da realidade social. Na análise do relativismo, que define como "um ponto de vista sobre o conhecimento as normas e os valores", Raymond Boudon (2009, p. I | 4) reflete sobre a contribuição conceitual de sociólogos e filósofos clássicos e modernos fazendo a defesa do bom relativismo em face do mau relativismo, já que se torna fundamental compreender contextos sociais e mentais diferentes que estão na base do relativismo normativo e do relativismo cognitivo.

Explorando-se o relativismo cognitivo a partir de análises em torno de paradigmas, de critérios de cientificidade e de quadros de construção e legitimação de crenças, constata-se que não há lugar para verdades absolutas e que a teorização é um processo que necessita ser questionado à luz de contextos muito diversos.

No quadro das ciências sociais e humanas, e segundo Stuart Hall, a teoria corresponde a uma forma concreta de interrogar, com vista à solução de problemas. A teoria é, assim, um conhecimento conjuntural, contestado, e não a verdade em si, já que a teoria tem o potencial de intervenção crítica, onde "o que importa são as rupturas significativas - em que velhas correntes de pensamento são rompidas, velhas constelações deslocadas, e elementos novos e velhos são reagrupados em redor de uma nova gama de premissas e temas" (2003, p. I 3 I).

A urgência da teoria é reclamada não só como forma de analisar a realidade social moldada pela globalização, rejeitando-se que o conhecimento seja 
o veículo de promoção de uma cultura traduzida em um "conjunto de atributos essencializados" que leva à sua objetificação e mercantilização (Almeida, 2007, p.88-89), mas também como princípio para ultrapassar a ilustração das experiências pessoais que conduzem à doxa.

Esses dois lados, que se aproximam e se distanciam no recuo e urgência da teoria, exigem que sejam repensadas questões conceituais, referentes às noções de objetividade e de verdade, sempre em conflito nas escolas de pensamento, e questões práticas, ligadas à finalidade dos sistemas educativos e do papel que é exigido da escola.

Quando se considera a educação como algo estritamente de natureza prática, deixando-se que no seu terreno de ação cresçam e floresçam formas conceituais de reduzir o conhecimento à "praticidade" dos contextos, sem que se discutam formas culturais e sociais de pertencimento, incorre-se no perigo da redução epistemológica e no empobrecimento do conhecimento educacional.

Perante a sociedade globalizada, urge retomar a teoria como forma de lançar a dúvida de uma forma sistematizada, de modo que o entendimento que se tem da realidade educacional esteja alicerçado em argumentos conceituais. Nesse sentido, teorizar é apresentar a dúvida, e a dúvida coloca-se pela interrogação. Ao existir entre as coisas e com as coisas e ao usar a faculdade da curiosidade, o estranho fazer do homem é o seu perguntar essencial no sentido da produção do conhecimento, definido do seguinte modo: "o conhecimento é aquele estado mental do homem que coincide com o que as coisas são" (Ortega y Gasset, 200 I , p.83 e 104).

E para tentar saber o que é a educação, torna-se necessário olhar para a teoria como interlocução na qual se baseia a criatividade humana e o "reconhecimento da comunicação - fala, conversa, diálogo - quando esta passa a constituir o direito humano à narração que é essencial à construção de comunidades diversificadas e não consensuais" (Bhabha, 2007, p.25).

Em reação a uma tendência de homogeneização e de coisificação do conhecimento, incrustada na natureza da globalização, e partindo do pressuposto que pertencer a uma cultura é reconhecer a sua perspectiva híbrida, Homi Bhabha sublinha que a interlocução "faz parte do processo de liberdade de expressão e da possibilidade do debate e interação dialógicos que criam as comunidades e as determinações políticas complexas", inserindo-se no que designa por dúvida global: 
A dúvida é uma hermenêutica das verdades: é uma prática social que consiste em questionamento próprio, inteligência crítica, decisão ético-política e interlocução social. É o processo pelo qual testamos as condições da verdade e as consequências práticas, pragmáticas, dos nossos atos como intervenientes no mundo. A dúvida global é crucial para a nossa noção do que está em causa quando nos afirmamos atores globais. (Bhabha, 2007, p.40)

É neste sentido que a teoria curricular é uma forma de conversação sobre os modos de produção de significados, que o conhecimento origina no quadro de contextos econômicos, sociais, políticos e culturais, com base na exploração da natureza profunda e complexa da condição humana ${ }^{4}$.

\section{TEORIAS DE INSTRUÇÃO E TEORIAS CRÍTICAS}

O que falta nas discussões atuais sobre o currículo é justamente alguma teoria do conhecimento (Moore, Young, 200I, p. 196). Sendo o alfa e ômega do currículo, o conhecimento passa a ser o elemento central ${ }^{5}$ da educação escolar, entendida nas suas múltiplas finalidades e nos seus processos e práticas de organização.

A afirmação de que "a ideia de currículo não está convenientemente apurada", devido à confusão de noções em torno das matérias de ensino e das unidades curriculares, é inaceitável (Gil, 2000, p.344) à luz da produção conceitual das últimas décadas no campo epistemológico dos Estudos Curriculares ${ }^{6}$.

4. Pinar e Grumet ( 1982 ) defendem a natureza humana como base crítica da educação, mas a partir do momento em que a relação teoria-prática não siga uma perspectiva instrumental e resgate, em parte, o sentido de contemplação, tal como era entendida a teoria na Grécia clássica.

5. Para a análise desta centralidade, ver Silva (2000) e Pacheco (2005).

6. A teorização tem sido marcada pela diversidade de abordagens, tal como referida em Pacheco (2005), em que estes autores são citados, sendo a mais utilizada, pelo menos em textos portugueses, a de Stephen Kemmis, proposta na base da teoria dos interesses constitutivos de Jürgen Habermas (técnico, prático e crítico), ainda que James Macdonald - teorias de controle, hermenêutica e crítica - tenha sido pioneiro, juntamente com William Pinar, que segue uma classificação idêntica para a denominação dos grupos de curriculistas (tradicionalistas, empiristas conceituais e reconceitualistas). 
Dada a diversidade que cada teoria curricular contém, sobretudo quando o princípio estruturante da educação vai sofrendo alterações conceituais que correspondem a uma ressignificação constante, é mais adequado o uso do termo teorias e não o de teoria para o estudo da realidade curricular. Perante a pluralidade de teorias, propostas à luz de diferentes campos disciplinares, com mais peso para os da Filosofia e Sociologia, e explorando a leitura do texto Teoria tradicional e teoria crítica, publicado originalmente em 1937, por Max Horkheimer, serão referidas as teorias de instrução e as teorias críticas ${ }^{7}$.

\section{Teorias de instrução}

A razão de ser da escola está ligada à transmissão de conhecimento, organizado curricularmente em disciplinas. Rob Moore e Michael Young (200 I , p. 198) afirmam que a "visão do currículo como um determinado corpo de conhecimentos a ser transmitido pela escola é tão antiga como a própria instituição escolar".

○ currículo como instrução é algo que perdura e que é o resultado não só da transmissão formal do conhecimento em espaços escolares, como também da ligação do currículo à consagração de uma educação nacional e à formação de uma política do cuidado. Na análise do Estado do Mundo, Bernard Stiegler analisa o conhecimento como ferramenta que singulariza o indivíduo no contexto de uma educação nacional, entendida como pilar da democracia industrial, no século XIX, e como chave da guerra econômica mundial, a partir do século $X X$, e baseado numa noopolítica:

que se assim se forma como sistema educativo constitui, nesse aspecto, uma noopolítica: uma política dos espíritos que permite a formação e a gestão de um espírito nacional ao serviço já não de uma fé religiosa ou de um poder político, teologicamente legitimado ou ditatorial, mas ao serviço de uma economia e de uma indústria nacionais que garantem também a possibilidade de uma promoção social dos indivíduos no interior do movimento de crescimento do saber do Estado-Nação exigido e permitido pelo desenvolvimento industrial. (2007, p. 149)

7. Para uma primeira abordagem desta problemática, ver Pacheco e Pereira, 2007. 
A tarefa de educar a população através de uma política do cuidado, que jamais se liga a pretensas neutralidades, como se a escola fosse a análise química da lágrima de uma preta, para utilizar a metáfora de António Gedeão, tem sido consagrada na instrução pública, gratuita, laica e obrigatória, "fazendo com que a população forme um povo, e não apenas uma população" (Stiegler, 2007, p. 153).

É em torno de uma educação nacional e de uma política do cuidado que se tem legitimado a teoria de instrução, ou as teorias de instrução, pois os processos e práticas de organização do currículo têm como fundamento a existência de um conhecimento escolar que impõe a homogeneidade funcional das aprendizagens. Nesse caso, "a ideia fantasiosa de que as comunidades nacionais se baseiam na hipersemelhança vingou", assim como progrediu a "ideia de que a homogeneidade cultural pode contrabalançar os efeitos antissociais da desigualdade social e econômica" (Gilroy, 2007, p. 17).

$\mathrm{Na}$ análise das vertentes instrucionais de uma teoria curricular tradicional, na linha de Max Horkheimer, identificamos duas concepções diferentes, a que correspondem formas de entender o papel da escola no cumprimento de uma educação nacional e de um currículo culturalmente homogêneo.

Uma primeira abordagem teórica do currículo pode ser situada na ordem enciclopédica da escola, ligada ao racionalismo acadêmico, com suportes conceituais na tecnologia de domesticação de espíritos, comportamentos e corpos. Nesse caso, a arquitetura de uma escola obedece a propósitos concretos, amplamente advogados por Comenius e Bentham, e criticados por Foucault, porque o conhecimento é de ordem disciplinar e a escola se torna o padrão da pessoa instruída, educada, vigiada, docilizada, controlada e performativa.

O racionalismo acadêmico está ligado ao conhecimento logocêntrico que impõe a soberania do magister mediante um currículo que não é mais do que a produção de sujeitos domesticados pelo saber, tal como se reflete na abordagem conceitual do tradicionalismo conservador, ou seja, "o que é importante é que a experiência de submissão de um sujeito às regras de uma disciplina escolar, de forma a torná-lo o tipo de pessoa que se espera" (Moore, Young, 2001, p. 199).

Quanto à segunda abordagem, ainda que o racionalismo acadêmico não esteja ausente das escolas, constata-se que a instrucionalidade do currículo tem sido legitimada por uma visão instrumental, primeiramente baseada na peda- 
gogia por objetivos e depois relacionada com a pedagogia por competências. No entanto, estas duas perspectivas, que têm como denominador comum o fato de traduzirem uma resposta a problemas econômicos, dentro do que Pinar (2007) designa por "reengenharia social da escola", incorporam noções diferentes de conhecimento, isto é, o conhecimento acadêmico (descontextualizado, abstrato) perde importância para o conhecimento utilitário (contextualizado, prático, relacionado com processos ativos).

A mudança paradigmática da década de 1970, em que se faz a passagem de uma abordagem tecnológica e burocrática para uma abordagem humanista, é um passo significativo para que os teóricos do currículo, reunidos na abrangente designação de teorias críticas, passem a analisar e compreender a educação à luz de outros critérios conceituais.

\section{Teorias críticas}

William Pinar, um dos nomes mais presentes nas discussões curriculares, é um dos que promoveram a ruptura epistemológica mediante a proposta teórica da "reconceitualização", enunciadora do currículo como um projeto que responde prioritariamente à dimensão humana do sujeito.

Se a mudança de paradigma foi consensual, permitindo a rejeição da lógica tyleriana da educação, a filiação dos autores a abordagens diferentes tem sido um pomo constante de discórdia. Por isso, o consenso dos autores ligados às teorias de instrução é simetricamente proporcional ao dissenso dos autores incluídos nas teorias críticas.

Verifica-se que as duas vagas conceituais da reconceitualização (política e pessoal) originaram divisões muito significativas no campo curricular, principalmente nos que seguem a vaga política e a vaga pessoal da análise e compreensão da educação. Tal divisão foi, e continua sendo, mais acentuada com a adoção das teorias pós-modernas e sua aplicação à educação, sobretudo quando se discute o currículo como prática cultural plural e quando se analisam as vantagens e/ou desvantagens conceituais do marxismo e do pós-marxismo.

Philip Goldstein (2005) sublinha que a importância do pós-marxismo, com que se identificam autores incluídos nas teorias pós-modernas, não está tanto em explorar o que representa a ideologia na análise do papel do sujeito na estrutura socioeconômica, mas sobretudo em reforçar as políticas dos 
grupos marginais e o papel dos discursos na rejeição de determinismos que impedem a compreensão do subjetivo nas práticas sociais, étnicas, raciais e sexuais. A representação do currículo como prática cultural ${ }^{8}$ é algo que pode ser explorado conceitualmente a partir das contribuições dos Estudos Culturais e da abordagem pós-colonial, reorientando-o para novas direções teóricas.

Todavia, os Estudos Culturais, que William Pinar (2007) critica como tentativa de aglutinar outros campos de saber, como o dos Estudos Curriculares, não podem se tornar um mero refúgio dos que lutam pela vertente política do currículo, do mesmo modo que o multiculturalismo não pode se converter em um discurso de reconhecimento superficial do vasto supermercado de culturas que desafiam a pretensa homogeneização cultural ligada à globalização ${ }^{9}$. Ao contrário, sua premência cultural pode ser explorada em educação de modo que o currículo seja entendido como um projeto construído na diversidade e na pluralidade não só na abordagem do conhecimento escolar, mas, de igual modo, no desvendamento de certos processos e práticas de poder e de padronização cultural que existem no interior das escolas ${ }^{10}$.

Talvez a tarefa mais crucial da teorização crítica do currículo, e seguindo as ideias defendidas por William Pinar, consista na problematização da educação a partir das identidades dos sujeitos, e suas relações com os outros, em ligação estreita com lugares e tempos de diferenciação social. Por isso, o currículo é uma conversação complexa que requer uma análise da autobiografia como prática investigativa e uma constante interrogação crítica dos modos da sua construção pessoal em tempos de pós-reconceitualização, ou seja, de questionamento constante de uma realidade que não pode ser compreendida fora da subjetividade.

É nesse aspecto que a obra de William Pinar, inicialmente influenciada por Paulo Freire, ajuda a compreender o papel da conscientização na teorização

8. Para a análise dessa perspectiva, ver, entre outros, Kanu (2006).

9. Gilroy (2007, p. 174 e p. 182) desenvolve a ideia de que se verifica atualmente a retirada institucional dos Estudos Culturais, fazendo com que os acadêmicos se refugiem em velhas disciplinas, pelo que "as fronteiras escolásticas, que pareciam ter começado a ser mais permeáveis e residuais, são mais uma vez entusiasticamente vigiadas". O revés do multiculturalismo está, por sua vez, associado a posicionamentos objetivistas e autoritários que consideram que ele fomenta o conflito, de que os atentados de Nova lorque e Londres são um exemplo.

10. Para uma análise da problemática do multiculturalismo em contextos escolares, ver Moreira e Candau (2008). 
do currículo, como propõe Kincheloe (2006), quando apela a novos níveis de consciência e modos de ser para a análise da educação, já que a ontologia crítica envolve a compreensão das relações entre os seres humanos em diversos níveis e a análise dos processos de construção do conhecimento.

Como prática de transformação, a conscientização, para William Pinar, em uma análise dos seus textos publicados desde a década de 1970 até a atualidade, expressa a mudança em dois momentos diferentes.

O primeiro está focalizado no esforço conceitual de compreender o currículo nas suas relações de subjetividade e dentro de uma valorização da dimensão humana, sempre presente na relação entre as esferas privada e pública. Esse esforço começou como uma consciência paradigmática para depois evoluir no sentido de uma consciência centrada na subjetividade. Explorando a educação como fonte de sentido, William Pinar aborda o currículo como um ato simbólico, cuja análise permite estudar os vértices de gênero, raça e queer presentes nas políticas de identidade. É com essa abordagem teórica que ele rejeita a estandardização do currículo, no sentido de uma orquestra, principalmente quando a administração educacional oferece aos professores e às escolas soluções técnicas.

O segundo momento diz respeito ao seu esforço para a internacionalização dos Estudos Curriculares, unindo esforços para que seja possível criar uma consciência subjetiva planetária, a que chama mundialidade, capaz de responder ao iminente colapso da biosfera.

○ currículo como conscientização é um projeto pessoal do trabalho acadêmico de William Pinar, bastante reconhecido. Por isso, seu papel não tem sido o de determinar o currículo, mas de lutar, contínua e persistentemente, no sentido de ajudar alunos e professores a refletir sobre suas experiências pessoais e sobre suas opções educacionais e curriculares.

E como a questão da teoria está ligada ao método, sobretudo quando se consideram as estruturas substantiva e sintática de uma disciplina (Schwab, 1964), que definem, respectivamente, seu corpus conceitual e seu método, é necessário relacionar a discussão teórica com o método, entendido neste texto como processo conceitual de questionar práticas de decisão curricular. Mais uma vez, recorremos a William Pinar, na medida em que se tem empenhado na proposta de um método, cujas fases analisaremos. 


\section{CURRERE COMO MÉTODO CURRICULAR}

Por estar profundamente imerso nas práticas curriculares, além de ter sido objeto de abordagens muito diversas, não falaremos neste texto do Rationale Tyler, ou do método de instrução, que nada mais é que a aplicação à educação das regras do método cartesiano.

A construção do currículo como experiência pessoal é chamada por William Pinar" de currere. Ele utiliza o conceito de experiência na continuidade da ideia husserliana de lebenswelt, para se referir à sua experiência existencial das estruturas externas. $\bigcirc$ método currere é a estratégia para desvendar essa experiência e torná-la mais clara.

Seguindo-se a etimologia latina, currere significa o correr, o registro de atividades numa relação biográfica que permite compreender a experiência educacional. Trata-se de colocar o individual no centro da discussão, não só por imperativo político e social, mas também por imperativo psicanalítico, na busca da relação do "eu" com o "outro". Por isso, esse método, de natureza autobiográfica, busca a explicitação da relação entre o que é considerado profissional e o que conta como pessoal, por um lado, e o que são as experiências contextualizadas dos educadores, por outro.

Não se restringindo a uma mera intenção, o método currere tem como raiz a noção freiriana de conscientização, entendida na perspectiva da práxis, que é reflexão e ação dos homens sobre o mundo para transformá-lo (Freire, 2006).

Realçando o papel do professor no desenvolvimento do currículo, bem como o conhecimento ligado aos contextos e às histórias de vida das pessoas, William Pinar propõe um método dialético que combina história e psicanálise, e que é sintetizado em quatro fases: regressiva, progressiva, analítica e sintética. Tais fases são momentos inter-relacionados para a compreensão da especificidade da experiência educacional a partir de uma relação histórica e de uma relação psicanalítica. Nos escritos mais recentes, Pinar (2009) retoma a questão do método currere, salientando os testemunhos pessoais e históricos para a construção do currículo.

Currere é um método de natureza autobiográfica que responde a esta questão central: qual é a natureza da experiência educacional?

II. Ver, entre outros, Pinar, 2006. 
Para o estudo e organização curricular da experiência educacional, o método currere utiliza princípios da fenomenologia e da psicanálise, e não propriamente os da psicologia e sociologia, porque no centro dessa experiência está o sujeito e a sua subjetividade. Daí que o método funcione como estratégia para que cada um de nós, como professores, possamos compreender nossas situações individuais e em grupo, na busca de uma relação constante entre as esferas pessoal (privada) e social (pública).

Nesse sentido, o método baseia-se na dialética para o estudo das experiências de vida e do currículo como conversação complexa, a partir de questões que dizem respeito aos sujeitos e não a interesses desencadeados por reformas educacionais voltadas para a reengenharia social.

A presença da autobiografia é contínua para William Pinar, quer pelo reconhecimento do lugar como categoria de análise, evitando que a subjetividade seja a expressão de uma perspectiva totalmente individualizada, quer pela afirmação de que as experiências pessoais são identidades ligadas à raça, etnicidade e orientação sexual (com relevo para a teoria queer), ou seja, que na compreensão analítica e sintética daquilo que somos, pessoal e socialmente, devemos buscar a relação constante entre o passado e o futuro.

A valorização da consciência histórica é um dos pontos fundamentais da obra de William Pinar que deve ser realçada, pois o entendimento que tem das questões culturais do currículo e de seus processos inerentes de produção de significados e identidades está ligada à noção de conscientização, sempre presente na sua obra acadêmica.

\section{CONCLUSÃO}

Voltando à discussão do Estado do Mundo, na qual se deveria usar a noção de conscientização para analisar criticamente forças globais que pretendem a homogeneização funcional da educação, mediante modelos curriculares determinados por forças econômicas, a análise do passado em termos (auto) biográficos é uma ferramenta de pesquisa que desempenha um papel central na análise educacional e curricular.

A esse respeito, e na linha do que William Pinar propõe, por sua visão crítica da educação e pelo método currere, diz Homi Bhabha: 
No entanto, ao contrário do que acontece com o futuro, não podemos "escoIher" o nosso passado cultural ou biográfico; podemos esquecê-lo num gesto de amnésia histórica; podemos reconstruí-lo de modo a que de adeqúe aos nossos interesses presentes; ou podemos condensá-lo no presente, a fim de demonstrar a continuidade da tradição cultural como parte da confluência de uma história partilhada. Em cada um destes casos, negociamos com o "passado" para transformar as nossas vidas; mas não podemos simplesmente escolher ou "desescolher" o passado. (2007, p.30)

Ao eleger a educação como alavanca da economia do conhecimento, a globalização, na busca de uma identidade de legitimação ${ }^{12}$, institui a lógica da competitividade na base do pressuposto de que o mundo pode se tornar uma imensa planície, fazendo com que a educação deixe em segundo plano sua missão de formação pública e cívica.

É nesse aspecto que o currículo necessita ser reinventado como um projeto crítico, quer juntando "as peças do passado e do presente"।3, quer analisando e sintetizando as identidades, tecidas entre os lugares do Eu e do Outro, que conferem significado ao que "entre-somos". Nesse contexto, ao sublinhar que as políticas identitárias referentes a raça, etnicidade e orientação sexual são instrumentos de construção do currículo, William Pinar coloca uma pedra no debate ideológico sobre a educação, e consequentemente sobre o predomínio da visão política, retomada pelos Estudos Culturais, transferindo-o para abordagens psicanalíticas e fenomenológicas.

Diante do recuo epistemológico abordado por Maria Célia Moraes, para quem a teoria não pode ser um mero discurso ou um jogo de linguagem incomensurável e sem sujeitos, e diante da urgência de problematizar a educação e o currículo como dinâmicas identitárias, na visão de William Pinar, trazer de volta a teoria significa abordar a teoria como ato de interlocução, em que se reconhece o diálogo como espaço de partilha, e relacioná-la com a prática,

12. Em dois textos anteriores, escritos com Nancy Pereira, questiona-se a globalização como processo de transformação mundial que envolve a redefinição do conceito de identidade, trabalhado a partir da obra de Manuel Castells. Ver Pacheco e Pereira (2007a e 2006).

13. Palavras de um poema de T. S. Eliot, As dry salvages, citado por Bhabha, 2007, p.30. 
mais no sentido de Max Horkheimer, para quem teoria é vigilância crítica, que se traduz no questionamento da realidade.

Assim, a educação e o currículo são projetos de questionamento, construídos na diversidade e pluralidade de marcas pessoais e sociais, compreensíveis na base de uma conversação complexa. Por isso, o currículo é um projeto de espaços e tempos subjetivos, com espaços e tempos sociais, vinculados aos sujeitos e seus modos de conversação, pelo que só poeticamente, pelo menos nas palavras de Clarice Lispector (2005), pode ser dito: "Experimento viver sem passado, sem presente e sem futuro... eis-me aqui livre".

\section{REFERÊNCIAS BIBLIOGRÁFICAS}

ALMEIDA, M. V. Da diferença e da desigualdade: lições da experiência etnográfica. In: BHABHA, H. K. et al. A Urgência da teoria. Lisboa: Tinta da China, 2007. p.75-77.

BHABHA, H. K. Ética e estética do globalismo: uma perspectiva pós-colonial. In: BHABHA, H. K. et al. A Urgência da teoria. Lisboa: Tinta da China, 2007. p.2I-44.

BHABHA, H. K. et al. A Urgência da teoria. Lisboa: Tinta da China, 2007.

BOUDON, R. O Relativismo. Lisboa: Gradiva, 2009.

ESTRELA, A. Pedagogia, ciência da educação? Porto: Porto Editora, 1992.

1999.

. O Tempo e o lugar das ciências da educação. Porto: S.P. C.E., Porto Editora,

FREIRE, P. Pedagogia do oprimido. 44. ed. São Paulo: Paz e Terra, 2006.

GIDDENS, A. A Europa na era global. Lisboa: Presença, 2007.

GIL, F. Disciplinas. In: ROMANO, R. (dir.) Enciclopédia Einaudi, I4: Conhecimento. Lisboa: Imprensa Nacional-Casa da Moeda, 2000. p.329-348.

GILROY, P. Multicultura e convivialidade na Europa pós-colonial. In: BHABHA, H. K. et al. A Urgência da teoria. Lisboa: Tinta da China, 2007. p. 1 67- 188.

GOLDSTEIN, P. Post-Marxist theory: an introduction. New York: State University of New York Press, 2005.

HALL, S. Da diáspora. Belo Horizonte: Editora da Universidade Federal de Minas Gerais, 2003. HORKHEIMER, M. Teoría tradicional y teoría crítica. Barcelona: Paidós, 2000. 
KANU, Y. Cultural as cultural practice: postcolonial imaginations. Toronto: University of Toronto Press, 2006.

KINCHELOE, J. Critical ontology and indigenous ways of being: forging a postcolonial curriculum. In: KANU, Y. (ed.) Cultural as cultural practice: postcolonial imaginations. Toronto: University of Toronto Press, 2006. p. | 81-202.

LISPECTOR, C. Aprendendo a viver: imagens. São Paulo: Rocco, 2005.

LYOTARD, J.-F. A Condição pós-moderna. 9.ed. Rio de Janeiro: José Olympio, 2006.

MOORE, R.; YOUNG, M. Conhecimento e o currículo na sociologia da educação: em busca de uma ressignificação. In: MOREIRA, A. F. (org.) Ênfases e omissões no currículo. Campinas: Papirus, 2001. p. 195-22.

MORAES, M. C. Recuo da teoria: dilemas na pesquisa em educação. Revista Portuguesa de Educação, v. I 4, n. I , p.7-25, 2001.

A Teoria tem consequências: indagações sobre o conhecimento no campo da educação. Florianópolis: Universidade Federal de Santa Catarina, 2008.

MOREIRA, A. F.; CANDAU, V. M. Multiculturalismo: diferenças culturais e práticas pedagógicas. Petrópolis: Vozes, 2008.

ORTEGA Y GASSET, J. O Que é o conhecimento? Lisboa: Fim de Século, 2001.

PACHECO, J. A. Estudos curriculares: para a compreensão crítica da educação. Porto: Porto Editora, 2005.

Políticas curriculares: referenciais para análise. Porto Alegre: Artes Médicas, 2003.

PACHECO, J. A.; PEREIRA, N. Estudos curriculares: das teorias aos projectos de escola. Educação em Revista, n.45, p. 197-221, 2007.

Globalização e identidades educativas: rupturas e incertezas. Revista Lusófona de Educação, n.8, p. 13-28, 2006.

Globalização e identidade no contexto da escola e do currículo. Cadernos de Pesquisa, v.37, n. 131 , p.371-398, 2007a.

PINAR, W. O Que é a teoria do currículo? Porto: Porto Editora, 2007.

.The Synoptic text today and other essays: curriculum development after reconceptualization. New York: Peter Lang, 2006.

The Worldliness of a cosmopolitan education: passionate lives in public service.

New York: Routledge, 2009. 
PINAR, W.; GRUMET, M. R. Socratic caesura and the theory-practice relationships. Theory into Practice, v.21, n. I, p.50-54, 1982.

RITZER, G. The Globalization of nothing, 2. London: Pine Forge, 2007.

SCHWAB, J. Structure of the disciplines: meanings and significances. In: FORD, G.; PUGNO, L. (eds.) The Structure of knowledge and the curriculum. Chicago: Rand McNally, 1964. p. I-30.

STIEGLER, B. Tomar cuidado: sobre a solicitude no século XXI. In: BHABHA, H. K. et al. A Urgência da teoria. Lisboa: Tinta da China, 2007. p. 143 - 166.

SILVA, T. T. da. Teorias do currículo: uma introdução crítica. Porto: Porto Editora, 2000.

TAYLOR, F. The Principles of scientific management. New York, 191 I.

Recebido em: agosto 2008

Aprovado para publicação em: março 2009 